\title{
The contribution of physicians to childhood injury prevention in France
}

\author{
B Lévêque, F Baudier, MP Janvrin
}

\begin{abstract}
Objectives-The objective of this study was to determine what injury control interventions are currently carried out by physicians and to examine how these interventions could be more effective.
\end{abstract}

Setting-Surveys were conducted among the three main groups of physicians who provide primary care to children in France - private practice pediatricians (PPPs), well-child clinic pediatricians (WCCPs), and general practitioners (GPs).

Method-A representative sample of each of the three groups of physicians were interviewed by telephone, using a computer assisted telephone interview system, in December 1993 or February 1994.

Results-Responses demonstrated that most physicians felt they could play an important part in injury prevention but that many had inadequate knowledge of injury related mortality rates in children. Most PPPs and WCCPs usually provided counseling on safety in relation to developmental changes in children. Few physicians gave recommendations about appropriate first responses to emergencies. Printed material, designed for parent education, was provided by many PPPs and WCCPs, but was usually absent from the offices of GPs. Participation in group education sessions was common among WCCPs but rare among PPPs and GPs. Many physicians expressed skepticism regarding the efficacy of their interventions in injury control.

Conclusion-A number of recommendations are made to those in government agencies or elsewhere who could help physicians to improve childhood injury prevention, for instance by regular publication of data on childhood injury mortality, counseling about parent education on this subject, and first aid in emergencies.

(Injury Prevention, 1995; 1: 155-158)

Keywords: survey, physician counseling.

Among those who seek to improve safety or public health in France, many would like to see physicians, especially pediatricians, play a more active part in the area of childhood injury prevention. Physicians can and should use medical encounters to educate parents about potential sources of injury in the environment and about injury control. Education on safety is, indeed, one of the two components of injury control, the other being development of regulations and standards to create safer environments.

Physicians are not the only source of information on injury control for parents. Government agencies and non-profit groups organize campaigns, using handouts, booklets, posters, press articles, and comments on the broadcast media. However, these community education efforts do not offer the same opportunities as a one-on-one encounter with a physician who can adjust his or her intervention to the personality of the parents - a considerable advantage when individual behaviors are involved, as is the case for injuries.

Physicians, in particular those in pediatrics, discuss prevention with parents when they recommend immunizations, a healthy diet, or proper dental care. These educational messages are given to parents during the 20 well-child visits required between birth and 6 years of age in France. After 6 years, school physicians continue the education effort.

Well-child visits in France are performed by three types of physicians, according to the parents' preference: private practice pediatricians (PPPs), well-child clinic pediatricians (WCCPs), and, less often, general practitioners (GPs).

Determining how physicians could better contribute to childhood injury control is only one facet of this problem of communication with the parent. ${ }^{1-4}$ There is also a need to obtain the opinion of physicians on this issue, based on their experience with injury prevention counseling. Generating and maintaining an interest in injury control among parents during a medical encounter is not an easy task. Some parents may not be motivated to engage in a discussion of injury prevention because they believe they are already well informed or that education is not within the province of the physician. Physicians may be unsure as to the best counseling strategy because they lack tools to evaluate the efficacy of their interventions. Another problem for physicians is finding enough time during visits to discuss injury control.

No data are available in France on the attitude of physicians toward their role in injury control. Such data, however, could help physicians to work more effectively and to plan visits in such a way as to make better use of the time available. To gather information on physician's attitudes toward their role in injury 
control, and to determine how government agencies or other organizations could help physicians educate parents, several organizations ${ }^{\star}$ worked together to survey French physicians.

Three surveys were carried out. Two were conducted in February 1994 among PPPs and WCCPs, using the same protocol. Similar data on GPs were previously collected in December 1993 during a survey conducted by the French Committee on Health Education (CFES) of the opinions of physicians about educational interventions. There were fewer questions on injuries in this survey than in the other two surveys, but they were formulated in the same way, making some comparisons possible.

\section{Methods}

Three hundred PPPs and 125 WCCPs were interviewed by telephone. The PPPs were selected at random from a telephone company list (SNAT file, France Télécom) while the WCCPs were chosen from physicians working at the 642 well-child clinics in the file of the CFES. GPs were selected from a file of all GPs practising in France. The proportions of physicians who declined to participate were $17 \%, 11 \%$, and $40 \%$ among PPPs, WCCPs, and GPs, respectively.

A computer assisted telephone interview system was used to directly enter interview data into a microcomputer. ${ }^{5}$ This system includes a number of automatic functions designed to improve the reliability of results. Results of the PPP survey were adjusted for data on gender, age, and geographic region (16 regions) provided by the National Social Security Office (Caisse Nationale d'Assurance Maladie). Statistical analysis was based mainly on univariate analyses using the Pearson $\chi^{2}$ test with the SPSS-PC computer program. ${ }^{5}$

\section{Results}

The responses of PPPs, WCCPs, and GPs to the questions were compared and formed the basis for this analysis.

\section{(1) ROLE IN INJURY PREVENTION}

When asked whether they felt that injury control counseling was part of their professional duties, $97 \%$ of PPPs and $99 \%$ of WCCPs answered yes. GPs were not asked this question.

(2) SOURCES OF INFORMATION (TABLE 1) Respondents cited medical journals as their main source of information. Other sources were used four times less often.

(3) EVALUATION OF KNOWLEDGE (TABLE 2) On average, responses denoted a fairly satisfactory level of knowledge. PPPs and WCCPs had generally accurate information about numbers of deaths due to falls, drowning, poisoning,

^APMS: Association des Sociétés d'Assurance pour la Prévention en Matière de Santé; CFES: Comité Français Prevention en Matière de Santé; CFES: Comite Français d'Education pour la Sante; CIRPAE: Centre d'Information et de Rencontre pour la Prévention des Accidents d'Enfants; an CSC: Commission de la Sécurité des Consommateurs.
Table 1 Sources of information about injury prevention. The question asked was: 'Among this list, which are the two sources of information on childhood injury prevention that you use most of ten??

\begin{tabular}{lll}
\hline Responses & $\begin{array}{l}P P P s \\
(\%)\end{array}$ & $\begin{array}{l}\text { WCCPs } \\
(\%)\end{array}$ \\
\hline Medical journals & 80 & 76 \\
Pediatric textbooks & 26 & 28 \\
Booklets for the general public & 21 & 25 \\
Continuing medical education & 32 & 31 \\
Media (broadcast and print) & 21 & 24 \\
Other & 20 & 16 \\
\hline
\end{tabular}

pedestrian-motor vehicle collisions, and motorcycle related or bicycle related injuries. However, many did not know that deaths due to fires are most common among toddlers, and that older children are at greater risk of death from motor vehicle occupant injuries than younger children. ${ }^{6}$

\section{(4) RECOMMENDATIONS TO PARENTS}

When asked whether they engaged parents in a discussion of injury control during medical encounters with children under 15 years who had no history of injury, $71 \%$ of PPPs, $79 \%$ of WCCPs, and $37 \%$ for GPs answered 'yes, very often' or 'yes, often'.

Physicians' recommendations centered mainly on safety rules and the need to adjust behaviors to developmental changes in the child. However, appropriate measures to be taken in severe injuries (bleeding, burns, asphyxiation) were discussed much less often (table 3). Interestingly, PPPs and GPs were more likely to offer first aid advice than WCCPs, whereas, for safety rules and developmental advice, the pattern was different, GPs giving such advice less often than the others.

(5) EDUCATION MATERIAL

Most physicians in all three categories $(77 \%$ of PPPs, $93 \%$ of WCCPs, and $85 \%$ of GPs) stated that some educational material was available at their office. However, in this survey, only $2 \%$ of GPs compared with $59 \%$ of PPPs and WCCPs provided material dealing specifically with injuries. Respondents felt that booklets designed for the public were the most useful type of educational material (table 4).

\section{(6) INJURY AWARENESS DISCUSSIONS}

Respondents were asked whether, during the last five years, they had been involved in any group discussions with adults outside the office setting, to talk about injuries and injury prevention. Responses varied substantially: $61 \%$ of WCCPs participated in such discussions compared with only $26 \%$ of PPPs and $21 \%$ of GPs.

\section{(7) EFFICACY OF PREVENTIVE EFFORTS}

The majority of physicians (table 5) believed that regulatory action was the most effective approach, since regulations are associated with the elimination or reduction of injury risks. In contrast, respondents expressed some skepticism about the efficacy of televised campaigns and of their own educational efforts. WCCPs 
Table 2 Highest rates of injury mortality by age in years ( $\%$ of answers). The question asked was: 'For each of the injuries in the following list, can you tell me in which age group mortality is highest?'

\begin{tabular}{|c|c|c|c|c|c|c|c|c|}
\hline & \multicolumn{2}{|l|}{$L 1-4$} & \multicolumn{2}{|l|}{$5-9$} & \multicolumn{2}{|c|}{$10-15$} & \multicolumn{2}{|c|}{$15-19$} \\
\hline & PPPs & WCCPs & PPPs & WCCPs & $\widehat{P P P s}$ & WCCPs & $\overline{P P P_{s}}$ & WCCPs \\
\hline Falls & 65 & 77 & 18 & 15 & 4 & 6 & 2 & 2 \\
\hline $\begin{array}{l}\text { Pedestrian-motor vehicle } \\
\text { collisions }\end{array}$ & 9 & 7 & 69 & 84 & 21 & 15 & 2 & 1 \\
\hline $\begin{array}{l}\text { Motor vehicle occupant } \\
\text { injuries }\end{array}$ & 23 & 31 & 30 & 24 & 7 & 8 & 4 & 10 \\
\hline $\begin{array}{l}\text { Motorcycle and bicycle } \\
\text { injuries }\end{array}$ & 1 & 3 & 10 & 6 & 48 & 46 & 51 & 69 \\
\hline Fires & 38 & 44 & 22 & 38 & 2 & 5 & 0 & 1 \\
\hline Drowning & 65 & 66 & 26 & 30 & 5 & 6 & 2 & 4 \\
\hline Poisoning by household & 92 & 95 & 11 & 12 & 2 & 0 & 1 & 1 \\
\hline
\end{tabular}

Table 3 Frequency of preventive recommendations about first aid, safety rules, or psychomotor development

\begin{tabular}{lccr}
\hline & $\begin{array}{c}P P P s \\
(\%)\end{array}$ & $\begin{array}{l}\text { WCCPs } \\
(\%)\end{array}$ & $\begin{array}{r}G P s \\
(\%)\end{array}$ \\
\hline First aid & & & \\
$\quad$ Very often & 9 & 2 & 5 \\
Often & 31 & 19 & 34 \\
$\quad$ Rarely & 43 & 66 & 52 \\
$\quad$ Never & 16 & 12 & 8 \\
Safety rules & & & \\
$\quad$ Very often & 52 & 60 & 14 \\
Often & 39 & 33 & 58 \\
$\quad$ Rarely & 7 & 5 & 25 \\
Never & 1 & 1 & 3 \\
Developmental advice & 46 & 66 & 9 \\
$\quad$ Very often & 37 & 29 & 61 \\
$\quad$ Often & 10 & 4 & 27 \\
$\quad$ Rarely & 3 & 0 & 3 \\
$\quad$ Never & & & \\
\hline
\end{tabular}

Table 4 Usefulness of educational material. The question asked was: 'Among the four following types of educational material, which do you believe is most useful for childhood injury prevention?'

\begin{tabular}{lll}
\hline & $\begin{array}{l}P P P s \\
(\%)\end{array}$ & $\begin{array}{l}\text { WCCPs } \\
(\%)\end{array}$ \\
\hline $\begin{array}{l}\text { Booklets for the public to be given to } \\
\text { parents }\end{array}$ & 48 & 55 \\
$\begin{array}{l}\text { Newsletters on injuries } \\
\text { Booklets dealing specifically with first } \\
\text { aid }\end{array}$ & 21 & 23 \\
$\begin{array}{l}\text { a single, complete dossier on } \\
\text { childhood injuries }\end{array}$ & 11 & 15 \\
\hline
\end{tabular}

Table 5 Effectiveness of preventive measures. The question asked was: 'Over the last 10 years, many measures have been taken to improve childhood injury prevention. Do you believe each of the following measures was effective, fairly effective, rather effective, or completely ineffective?"

\begin{tabular}{lll}
\hline & $\begin{array}{l}P P P s \\
(\%)\end{array}$ & $\begin{array}{l}\text { WCCPs } \\
(\%)\end{array}$ \\
\hline Regulation & 97 & 90 \\
Public education & 54 & 60 \\
Parents' education & 62 & 75 \\
Child education & 61 & 75 \\
\hline
\end{tabular}

were somewhat more confident than PPPs that their interventions were useful.

\section{Discussion}

These surveys revealed several important findings of relevance to the identification of injury prevention needs. Many of these deficiencies could be met rapidly.

The fact that most physicians expressed a desire to participate in injury prevention is important and consistent with results of a recent survey among British physicians. ${ }^{7}$ How- ever, physicians cannot be expected to maintain this positive attitude unless they receive support, guidance, and encouragement. This is especially true because many physicians have justifiable doubts about the efficacy of their counseling efforts. In the British survey, only $23 \%$ of physicians were satisfied with their role in injury control; the others felt they did not have enough time or knowledge to engage in effective counseling on childhood injuries. ${ }^{7}$ Physicians need more evidence that their efforts are fruitful. Such evidence can only be provided by evaluations such as that conducted by Bass et al in the United States. ${ }^{8}$ They clearly demonstrated that childhood injury prevention counseling can lead to risk reducing behavioral changes provided it is part of a standardized program (for example, the Injury Prevention Program developed by the American Academy of Pediatrics) and that is reinforced by other actions focusing on the same problem (for example, regulations on water heater temperatures and child car seats. The French Ministry of Health and National Social Security office, which should play the leading part in childhood injury prevention in France, must provide similar support to physicians. One simple measure would be to supply physicians with data on the results of preventive efforts, for instance by publishing each two or three years morbidity and mortality statistics showing trends over time.

Our survey also demonstrated that physicians do not provide parents with adequate counseling or printed information about first responses to emergencies. This is of concern because the outcome of some childhood injuries depends to some extent on the appropriateness of this response. In addition, educating parents about how they should respond to emergencies may enhance their awareness of their responsibility with regard to childhood injuries. Regardless, more efforts are needed to educate both physicians and parents on how to deal with emergency situations.

A third finding is that considerably fewer PPPs and GPs than WCCPs participate in safety discussions with groups of adults. This difference is probably due to the fact that PPPs and GPs are private practitioners whose main role is to provide individual health care, whereas French WCCPs work in non-profit clinics whose focus is public health, including screening, and prevention.

Another possibility is that PPPs and GPs may be reluctant to participate in group education sessions because they lack knowledge of childhood injury prevention or are uncertain how best to conduct such discussions.

Physicians need assistance to help them enhance their group education skills, especially as recently developed World Health Organization programs promoting safe communities require the participation of the medical profession. These programs have been proved effective, in particular in Sweden ${ }^{9}$ and it is hoped that they will be introduced in France. They require that all those involved with childhood injuries in a community establish clear-cut injury prevention objectives and 
reliable procedures to evaluate their efforts. The role of physicians and other health care professionals in these programs is to enhance injury control awareness by counseling individuals and participating in group sessions.

It seems evidence from our surveys that physicians need more printed information on injuries. Since physicians use medical journals as their main source of information, these journals should publish more articles on childhood injuries. Many pediatric journals in other countries, in particular the United States, publish far more original articles and review articles on childhood injuries than do journals in France.

GPs appear to be much less committed to childhood injury control than PPPs and WCCPs. Efforts are needed to enhance their awareness of and willingness to participate in this area of prevention. Caring for children represents $30 \%$ to $40 \%$ of the workload of GPs in France. Parents who choose a GP for their child should be as well informed about childhood injury prevention as those who choose a PPP or WCCP.

\section{Conclusion}

Our surveys provide data on the part currently played by physicians in France in childhood injury prevention via parent counseling. Physicians require more assistance aimed at refining their educational skills, and guidance about the most effective counseling strategies.

This assistance could be provided by several sources, including government agencies, pediatric journals, and non-profit organizations, such as those that conducted this study. Such organizations should intensify their work with the medical profession with the goal of improving public health.

1 Jackson RH. The doctor's role in the prevention of accidents. Arch Dis Child 1988; 63: 235-7.

2 Gordon S, Smith MB. The physician's role in injury prevention. F Gen Intern Med 1990; 5 (suppl) S67-73.

Glotzer D, Weitzman M. Childhood injuries. Issues for the family physician? Am Fam Physician 1991; 44: 1705-16.

4 Sibert JR. Accidents to children: the doctor's role. Education or environment change? Arch Dis Child 1991; 66: tion or

5 SPSS Inc. Statistical package for social science reference guide.

New York: SPSS Inc, 1992: 1-792.
6 Lion J, Hatton F, Maguin P, Maujol L. Statistiques des causes médicales de décès. Paris: INSERM, 1990: 1-243.

7 Carter YH, Jones PW. General practitioners beliefs about their role in the prevention and treatment of accidents involving children. Br $\mathcal{F}$ Gen Pract 1993; 43: 463-5.

8 Bass JL, Christoffel KK, Widome M et al. Childhood injury prevention counseling in primary care settings. A critical review of the literature. Pediatrics 1993; 92: 544-50.

9 Svanstrom L. Anderson B, Graham I, Moerup T, OzanneSmith J, Roberts H. How to develop safe communities. Proceedings of the Second World Conference on Injury Proceedings of the Second Wor
Control, Atlanta 1993; 241-2.

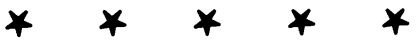

\section{More adventures of an injury-prone editor}

Several readers commented on the anecdote in the first issue describing the 'adventures of an injury-prone editor'. They may be further amused to learn that three days before participating in a state of the art plenary session on injury prevention at a large international meeting of pediatric societies, I mounted a ladder to remove a winter bird-feeder. (It was May, and winter in Montreal had finally ended!) The feeder was out of reach so I placed the ladder on a bench, climbed up carefully, reached out, leaned over, toppled, and fractured my heel! Three days later, supported by crutches, I explained to the audience that my wound was not an 'accident'; it was an 'injury' because it was easily preventable. It occurred because advancing old age had affected my brain, as well as the rest of my body. For, as I said, it is well known that 'Time wounds all heals!' 